\title{
Multilinguales
}

\section{Enseigner la culture de l'autre : la tentation culturaliste}

Teaching the 'culture' of the other : the culturalist temptation

\section{Regis Machart et Sin Zi Chin}

\section{(2) OpenEdition}

1 Journals

\section{Édition électronique}

URL : http://journals.openedition.org/multilinguales/1559

DOI : $10.4000 /$ multilinguales. 1559

ISSN : 2335-1853

\section{Éditeur}

Université Abderrahmane Mira - Bejaia

\section{Édition imprimée}

Date de publication : 1 juin 2014

Pagination : 21-36

ISSN : 2335-1535

\section{Référence électronique}

Regis Machart et Sin Zi Chin, «Enseigner la culture de l'autre : la tentation culturaliste », Multilinguales [En ligne], 3 | 2014, mis en ligne le 03 juin 2014, consulté le 17 septembre 2019. URL : http:// journals.openedition.org/multilinguales/1559; DOI : 10.4000/multilinguales.1559

Ce document a été généré automatiquement le 17 septembre 2019.

\section{(i) $\odot$

Multilinguales est mise à disposition selon les termes de la Licence Creative Commons Attribution Pas d'Utilisation Commerciale - Pas de Modification 4.0 International 


\section{Enseigner la culture de l'autre : la tentation culturaliste}

Teaching the 'culture' of the other : the culturalist temptation

Regis Machart et Sin Zi Chin

1 Que ce soit dans les discours politiques, ou dans le quotidien ou encore en didactique des langues, force est de constater que les références à la culture sont omniprésentes sous une forme ou une autre, qu'il s'agisse de définir des caractéristiques culturelles d'un groupe afin de mieux l'appréhender, l'intégrer ou le bannir, ou dans une optique davantage inter-personnelle, relationnelle, interculturelle, même si ce dernier terme gagnerait à être mieux défini dans les discours des uns et des autres.

2 L'intégration de la dimension culturelle en didactique n'a pourtant pas toujours été évidente (que l'on pense aux méthodes audio-orales par exemple) et l'association d'une langue à une culture n'a rien de systématique. Tout d'abord parce qu'une langue peut être partagée par des individus d'horizons bien différents. Ensuite, parce que dans des contextes où la langue est utilisée comme lingua franca, elle perd parfois de son ancrage territorial et relationnel, pour ne devenir qu'un outil de communication entre individus dont ce n'est pas la langue première. Ces situations de communication « interalloglotte » (Behrent, 2010) semblent en effet encourager un découplage langueculture, comme cela se fait dans le cas de l'anglais en Malaisie (Machart, Lim et Lim, 2010), même si certains peuvent le regretter : Phillipson (2008) n'hésite pas à qualifier l'anglais lingua franca (désormais ALF) de «lingua frankensteinia », soulignant l'horreur que ce concept peut soulever. Jennifer Jenkins (2007) considère cependant que l'ALF n'est pas une espèce de variété mi-humaine, mi-monstrueuse, mais que le terreau culturel auquel il est associé prend d'autres contours, davantage globalisés et moins nationalement ancrés.

3 La situation de la Malaisie en ce domaine peut se révéler éclairante. Entre 80 et 120 langues sont parlées sur le territoire de fédération, pour une population d'environ 26 millions. L'anglais est largement utilisé lors des contacts entre individus d'origines ethniques différentes (Kachru et Nelson, 2006 : 186) même lorsqu'aucun locuteur natif n'intervient dans l'échange. L'anglais est la langue seconde des Malaisiens (Asmah, 
2009), qu'ils soient d'origine malaise, chinoise, indienne ou autre, et ce, même si le système scolaire laisse parfois une place importante à leur langue première dans le cas du malais, du mandarin ou du tamoul (Machart et Lim, 2013a). L'enseignement des langues étrangères comme le français n'intervient donc qu'en surimposition d'une architecture complexe mêlant langue maternelle, langue de scolarisation, langue(s) de socialisation et parfois d'autres langues autochtones ou variétés de chinois, ainsi que l'anglais (Lim et Machart, à paraître). On peut se poser la question du positionnement des enseignants des langues étrangères, ici le français, parfois cinquième, sixième langue ou plus, quant à la culture-cible dans ce contexte où parler une (des) langue(s) n'inclut pas une compétence culturelle revendiquée.

4 Houssaye (1992: 41) représente la situation pédagogique sous forme d'un triangle avec, à chaque extrémité, un acteur : enseignant, apprenant ou savoir. Deux des sommets du triangle ont déjà été étudiés : (1) les manuels, importés de France, qui influencent les représentations des langues (Maurer, 2013:27) et de leurs locuteurs ont fait l'objet d'un ouvrage publié par Zarate (2004) soulignant les idéologies sous-jacentes à leur conception; (2) les recherches sur les représentations et attitudes des apprenants malaisiens quant aux langues étrangères (LE) se développent de plus en plus (Machart, Lim et Lim, 2010). Restait à explorer les représentations des enseignants (le troisième angle), dans une approche critique.

5 A la diversité des profils des apprenants, s'ajoute celle des parcours professionnels des enseignants des programmes de français: natifs ou non-natifs, eux-mêmes plurilingues, formés en France et/ou en Malaisie. Leur effectif (13 au moment de notre recherche) peut sembler limité : ils constituent cependant la population mixte la plus nombreuse enseignant une LE en Malaisie (l'autre LE, l'allemand, est enseignée presque exclusivement par des enseignants internationaux). Quelles représentations de la culture et de son enseignement se font donc ces enseignants de français ? Quels sont les fondements théoriques auxquels leurs discours sur la culture et l'interculturel peuvent se rapporter? Nous illustrerons les ambiguïtés de la présence de la culture dans la classe de langue en nous appuyant sur des entretiens menés avec douze d'entre eux.

\section{De la culture à l'interculturel}

6 Si l'approche différentialiste de la culture, telle qu'elle se pratique parfois encore, remonte à Herder (Wimmer, 2013) et peut être associée à la montée des nationalismes des XVIIIe et XIXe siècles (voir par exemple Thiesse, 1999), les recherches plus récentes sur l'interculturel liquide sont dans la lignée des travaux de Martine Abdallah-Pretceille (1986). Elles encouragent à sortir du «nationalisme méthodologique » (Dervin, 2013), c'est-à-dire à sortir des stéréotypes nationaux pour s'engager dans une démarche de type socioconstructiviste (Holliday, 2010) incluant une forme de diversité qui ne réduit pas l'individu à une culture (Dervin, Machart et Byrd Clark, 2013), que nous appellerons ici diversité liquide.

7 Cette approche liquide ou fluide s'oppose à une approche solide (Bauman, 2001) et herderienne de la culture relativement statique qui enferme les individus dans des catégories (nationales, raciales, ethniques ou culturelles). Dans Impostures interculturelles, Fred Dervin (2012) dénonce en détail cette dernière et plaide pour la fluidité qui, selon l'auteur, est la seule possible afin de redonner sa place à l'individu et sa faculté de jugement. Ainsi, une personne n'est-elle pas le simple produit d'une 
histoire dans un endroit donné, mais aussi un acteur de cet espace-temps qu'elle peut choisir d'adopter, de renier ou de manipuler, etc. malgré ou en fonction des contingences de l'interaction. Ce chercheur note cependant que de nombreuses contributions prétendent s'éloigner de l'enfermement culturel et revendiquent une certaine fluidité sans pour autant l'intégrer complètement; ils continuent ainsi à générer des stéréotypes plus ou moins modulés (mettant en garde contre les généralisations, par exemple), démarche que Dervin qualifie de janusienne, en référence au dieu romain à deux têtes. En développant encore davantage son raisonnement, Dervin appellera la prise en compte de la fluidité dans l'analyse des échanges Mixed Intersubjectivity ou MI (2013) qui permet de faire resurgir les voix visibles et invisibles en action dans les discours dits interculturels.

8 La MI implique de sortir des stéréotypes auxquels nous convient indirectement les méthodes de langues souvent conçues dans les pays où la langue cible est langue nationale et qui font office de vitrine promotionnelle (Zarate, 2004): les réussites techniques telles que le TGV ou Ariane continuent d'être représentées en bonne place. Les manuels présentent souvent de grandes catégories (les Français, les immigrés) ou de vastes espaces (le Sud-Ouest), et enferment les locuteurs d'une langue dans une « culture imaginée » (Dervin, 2006). Abdallah-Pretceille (1999: 121) nous met en garde contre cette tentation culturaliste qui, selon elle, ne permet pas d'aller réellement à la rencontre de l'Autre, cette personne qui est transformée en un objet culturel ou en simple "ambassadeur» d'une culture supposée par une approche essentialisante. Toutes les interactions prennent dès lors un tour culturel et les actions les plus anodines sont vues à travers des «lunettes culturelles " (Breidenbach et Nyiri, 2009) nécessairement déformantes, au lieu de favoriser un "humanisme du divers» (Abdallah-Pretceille, 1999 ; 2012).

On peut blâmer les ouvrages et documents utilisés en classe : ils ne sont cependant que des supports entre les mains des enseignants qui sont (souvent) libres de les choisir, de les rejeter ou de les adapter. Il est nécessaire qu'ils soient relativisés afin de prévenir les biais d'interprétation. Lacassagne et al. (2001) ont mis en évidence toute une série de biais lors de la mise en mot d'un exogroupe : (1) le biais de contraste qui accentue les différences entre les Mêmes et les Autres, (2) le biais d'assimilation qui tend à faire des membres d'un autre groupe des individus aux comportements davantage similaires aux membres de sa propre communauté, et (3) le biais de discrimination consécutif, qu'il soit positif (idéalisation, admiration) ou négatif (dénigrement, rejet).

Si ces penchants restent courants dans la catégorisation des Autres, le rôle de l'enseignant reste la formation de ses apprenants et de nombreuses voix s'élèvent pour combattre les stéréotypes. Cependant, même si la formation actuelle fait une large place aux compétences au détriment des savoirs (Volle, 2014), la formation interculturelle prend souvent le sens inverse, favorisant les savoirs plutôt que les savoir-être ou savoir-faire. La saillance des cours de Didactique de la Culture par opposition à l'intitulé Didactique de l'Interculturel est emblématique, et même dans ce dernier cas, il convient de questionner ce qu'on entend par interculturel.

Welsch (1999) tient à se démarquer du concept d'interculturel qui, dit-il, est statique et ne fait que mettre en contraste des cultures différentes sans prendre en compte le processus d'interaction: "Le concept d'interculturalité essaie de trouver le chemin que ces cultures peuvent tout de même emprunter, pour se comprendre et se reconnaitre " (p. 197, notre traduction). Il considère qu'un changement de paradigme est nécessaire et il 
revendique l'utilisation du terme transculturel, contre l'homogénéisation des cultures et pour une prise en compte des individus. Il est vrai que interculturel est devenu tellement caméléon (Lavanchy, Gajardo et Dervin, 2011: 1) que son utilisation ne permet a priori pas de comprendre le positionnement des auteurs. Dans cette contribution, nous donnons à interculturel une dimension fluide, interactionnelle dépassant les catégories culturelles ou nationales dans la lignée des travaux d'AbdallahPretceille, Holliday ou Dervin. Nous sommes conscients que le terme est largement usurpé, à l'image des termes connexes d' "identification", concept fluide utilisé de façon statique (Machart et Lim, 2013b), ou encore « diversité » (Dervin, Machart et Byrd Clark, 2013). Seul un positionnement clair des auteurs permet de lever l'ambiguïté.

Afin de comprendre leur ancrage théorique, nous avons mené douze entretiens semidirectifs avec quatre hommes et huit femmes qui enseignent dans les programmes de licence des deux universités publiques en Malaisie où ce cours est offert; ce qui représente $92 \%$ des effectifs d'enseignants : trois sont locuteurs natifs (NL1, NL2 et NL3) et neuf non-natifs (ci-après NNL1, NNL2 NNL3, etc.). Au moment de cette enquête, tous les locuteurs natifs avaient fait leurs études supérieures en Europe et ils enseignaient la langue et la culture françaises en Malaisie, aux apprenants de différentes ethnies depuis plus de huit ans. Les locuteurs non-natifs avaient fait leurs études supérieures en France et en Malaisie selon les programmes de formation mis en place par le Ministère de l'Education malaisien (Riget, 2014). En outre, leur expérience d'enseignement du français en Malaisie s'étendait de cinq à 34 ans. Nous avons volontairement masqué leur genre dans les extraits qui suivent afin de préserver leur anonymat.

\section{Langue-culture, la relation ambiguë}

13 L'association langue-culture est courante, sans pour autant recouvrir la même réalité : pour certains, la langue est la culture, en particulier chez les nationalistes des XVIIIe et XIXe siècles, alors que pour d'autres la langue génère de la culture, et la culture se fait par la langue (mais pas seulement). Ces derniers préfèrent parler d'identification culturelle par la langue, insistant sur les procès et espérant se distancer des identités statiques (Machart et Lim, 2013). Les extraits suivants sont caractéristiques des réponses fournies par les participants: ils révèlent une approche identitaire de la culture et un fort lien de la langue avec la culture en contexte de didactique des langues étrangères :

\section{Extrait 1}

NNL7/ 9 : [...] La langue montre la culture des gens. Comment ils sont, comment ils... comme ils sont, s'ils sont bons. Parfois, en utilisant la langue on connaitt la culture d'un groupe et les autres.... La langue et la culture viennent ensemble, et la langue montre toujours.... En utilisant la langue, on peut montrer la culture de certains groupes.

L'approche de NNL7 est particulièrement solide et on peut y déceler une idéologie sousjacente héritière directe de l'idéologie européenne du XVIIIe: un peuple (ici une culture), une langue (Thiesse, 1999 : 67). La langue y apparaît comme un concept idéal découplé des pratiques réelles, si ce n'est que l'utilisation de ce code (et non comment la langue est utilisée) inscrit les locuteurs dans un groupe particulier. On peut alors parler de fonction emblématique de la langue. Or la langue est activée différemment selon les 
régions. Charaudeau (2001) souligne ainsi que le français tel qu'il est actualisé en métropole diffère du français du Québec et il préconise une association discoursidentité culturelle au lieu de focaliser sur la langue. Même si avec Charaudeau on s'inscrit dans une certaine forme de nationalisme méthodologique ancrant les locuteurs dans un cadre national/régional, le modèle a l'avantage de prendre en compte une certaine fluidité du discours que NNL7 semble ignorer.

La référence à la culture apparait ici comme classifiante : « comme ils sont, s'ils sont

bons ». Les processus de catégorisation apportent souvent une discrimination sous une forme ou une autre (Lacassagne et al., 2001), et l'objectif semble bien ici de se positionner par rapport à un autre groupe, ici les Français. NNL7 ne livre cependant pas son jugement final à INT mais nul doute qu'il/elle se positionne personnellement par rapport à ces Autres.

La représentation de la culture NNL7 s'accommode mal de la situation malaisienne, où de nombreux locuteurs d'une langue sont associés à une autre culture. Ainsi, les BabaNyonyas de Melaka des anciennes générations parlent une variété de malais tout en s'identifiant à la culture chinoise, tandis que les plus jeunes s'expriment en chinois et revendiquent une identité baba-nyonya (Machart et Lim, 2013b). Par ailleurs, l'anglais est quotidiennement utilisé par un quart de la population (Mc Arthur, 2002) et certains Malaisiens le revendiquent comme leur langue première, sans s'identifier comme Britanniques. L'utilisation d'une langue comme lingua franca est ici occultée et la langue devient un marqueur identitaire bien plus qu'une pratique, au même titre peutêtre que les costumes traditionnels ou la cuisine.

La connaissance de la langue entre donc dans une sorte d'offre globale incluant nécessairement la culture, ce que confirme l'extrait suivant :

Extrait 2

INT 7 : Est-ce que vous pensez qu'enseigner la culture française aux étudiants [de licence] est important?

NL3 7 : D'après toi ?

INT 7.1 : Hmm....je pense que pas vraiment...

NL3 $7.1:$ :...] Si tu n'es pas intéressée par la culture française, ne fais pas des études de français ! Je veux dire à quoi ça sert ? Tu ne pourras jamais devenir traducteur si tu ne connais pas la culture, ce n'est pas possible, on ne peut pas devenir traducteur si on ne connait pas la culture. Ce n'est pas possible. Alors ce n'est pas la peine d'apprendre la langue si on n'apprend pas la culture. C'est un fait. Seulement comme comparaison, c'est bien mais c'est comme étudier les poissons sans étudier l'eau.

Lorsqu'INT pose la question à NL3, il/elle lui retourne la question, espérant trouver une alliée en INT. NL3 semble pris(e) au dépourvu par la réponse de celle-ci et se retrouve à essayer de justifier une association langue-culture plus que solide. INT a suivi une formation en français (ce qui a été dit à NL3 avant l'entretien), mais à aucun moment, INT n'a émis l'idée de devenir traductrice. La représentation de l'apprenant de français qui chercherait à acquérir la compétence d'un locuteur natif (la profession de traducteur peut être ici aisément extrapolée) ne correspond, dans son ensemble, que peu aux désirs des apprenants malaisiens qui, pour la plupart, se tournent à la fin de leurs études vers des professions peu en relation avec le français, où la langue est utilisée de façon "utilitaire»: stewards et hôtesses de l'air, banques et commerce (accessoirement en français) ou hôtellerie. La compétence d'un locuteur natif ne semble pas être un objectif des apprenants malaisiens qui marquent peu la différence 
entre les enseignants natifs et non-natifs, certainement parce qu'ils sont eux-mêmes plurilingues sans vraiment maitriser leur seconde, troisième ou quatrième langue (Machart, Lim et Choong, 2011).

La réponse de NL3 correspond donc davantage à sa propre projection et à une attente utopique: INT s'intéresserait à la culture (risquerions-nous Culture avec une majuscule ?) française. A aucun moment, NL3 ne se pose la question de savoir de quelle culture on parle, bourgeoise ou anthropologique. Le mot est utilisé comme allant de soi, alors que les études récentes relativisent largement le concept et cela devient un « fait » que la maitrise de la langue passe nécessairement par la maitrise de la culture. La vox populi a parlé. On notera l'emploi de l'impératif, marquant le rôle de conseiller ou en tout cas d'enseignant que NL3 assume lors de l'interaction, fortement asymétrique, alors que INT invitait à une réflexion.

\section{Enseigner la culture}

Pour des enseignants, la question du transfert du savoir se pose obligatoirement, c'està-dire la relation établie entre le savoir et l'enseignant (Houssaye, 2000). Comment des enseignants aux profils variés envisagent-ils d'articuler leurs représentations de la culture auprès d'un public hétérogène?

\section{Extrait 3}

INT 3 : Comment enseignez-vous la compétence interculturelle à vos étudiants ?

NNL3 3: On essaie autant que possible de faire des comparaisons, comme en Malaisie, c'est ce que vous faites normalement, en France normalement c'est ce qu'on fait, pourquoi c'est comme ça... On essaie d'expliquer, peut-être que ce n'est pas juste, mais pour leur faire comprendre pourquoi en France on ne peut pas faire ça, pourquoi dans notre culture, c'est permis de faire comme ci et comme ça, Normalement, on va... j'essaie de faire les comparaisons et j'essaie d'expliquer autant que je peux pourquoi c'est comme ça, pourquoi c'est permis dans notre culture, pourquoi ce ne l'est pas dans la leur. Mais il faut fouiller un peu dans l'histoire pour savoir pourquoi quelque chose est permis, pourquoi quelque chose... ça, il faut que tu les cherches un peu.

NNL3 se positionne comme enseignant(e). Ses exemples ("On essaie d'expliquer », « on va ») lui permettent de s'inscrire dans un discours pédagogique et de bâtir son discours avec le soutien invisible et supposé de ses collègues (la «voix invisible» de Dervin (2013)). NNL3 s'oppose donc ici à INT, tout comme NL3 l'avait fait. A défaut de culture linguistique (NL3 est natif-ve, NL3 ne l'est pas), nous assistons à un positionnement dans le discours par la place administrative et le statut social (enseignant-e vs étudiante) dans une relation hiérarchique forte.

Plus tard dans l'entretien, NNL3 se rapproche de l'interviewer (" dans notre culture ») et les limites deviennent nationales. On relèvera toute l'ambiguïté de notre dans un pays revendiquant le multiculturalisme et où on serait bien en difficulté de définir une culture nationale même dans les discours politiques officiels. Quelle est donc cette culture commune à laquelle l'enseignant ferait référence? Les discours de chercheurs (mais pas seulement) font apparaitre une "passion » pour les catégories raciales (Lim, 2008) et ce passage montre à quel point la notion de culture peut être manipulée au cours d'une interaction afin de créer une certaine connivence (nationale? ethnique ?) qui avait été refusée à INT ultérieurement. 

et amène nécessairement à stéréotyper une population. Même si on se place au niveau ethnique, Malais, Chinois, Indiens et autres se retrouvent ici partager une même culture («notre culture »), et même chez les Français, toute diversité (au sens liquide) est occultée : "en France, on ne peut pas faire comme ça », "Ce n'est pas dans la leur »). L'expérience individuelle plurilingue et pluriculturelle d'individus évoluant dans un contexte multiculturel et multilingue se résume au « clash » des cultures dénoncé entre autres par Welsch (1999) et Dervin (2012). quelque chose est permis ») donne à la culture un certain poids, mais occulte l'évolution de toute société. Ce qui était permis à un moment donné, ne l'est peut-être plus quelques années plus tard. NNL3 cherche à inscrire les individus dans un passé révolu, dans une identité historique. La comparaison semble être la méthode utilisée par défaut ; et même lorsqu'une plateforme commune nécessaire au bon déroulement de l'échange est recherchée, elle est située entre deux cultures, alors que ce sont deux individus qui se rencontrent (Chin, 2013) et non pas deux concepts imaginaires :

Extrait 4

INT 3 : Comment enseignez-vous la compétence interculturelle à vos étudiants ?

[...]

NL1 3.2: Je demande aux étudiants comment les Malaisiens font [...] J'essaie toujours de montrer ce qu'on fait toujours en France, et ensuite je demande aux étudiants si c'est la même chose en Malaisie, ou si ce n'est pas la même chose. Cela peut-il dire la même chose? Et ensuite, je demande aux étudiants d'expliquer ce que cela signifie dans la culture malaisienne. Et ensuite, on essaie de se rencontrer au milieu, entre ce que cela signifie dans la culture française et ce que cela signifie dans la culture malaisienne [...].

Les oppositions systématiques, «en France »/«en Malaisie» - «les Français»/«les Malaisiens », opérées ici par un-e natif-ve nous montrent que c'est la méthode la plus communément employée. Alors que NNL3 aurait eu du mal à définir ce qu'est la culture malaisienne, si la question lui avait été posée (elle aurait occulté forcement nombre de ses composantes), NL1 (de même que NL2 et NL3) a un parcours personnel complexe : tous les natifs interviewés sont plurilingues, ont une longue expérience d'expatriation, et ne correspondent pas aux stéréotypes de la "culture imaginée » (Dervin, 2006) française qu'ils essaient de véhiculer. Il est quand même assez paradoxal que des individus aux parcours si divers inscrivent les Français dans un modèle figé qu'ils vont ensuite vouloir essayer de moduler.

\section{Fuir (vainement ?) les stéréotypes}

Les stéréotypes se retrouvent à tous les paliers de la situation didactique : soit qu'ils existent en amont dans le stock représentationnel des apprenants et des enseignants et qu'ils sont susceptibles d'émerger à tout moment dans les situations d'apprentissage (Béacco, 2000), soit qu'ils sont convoqués en classe par l'entremise des ouvrages ou du matériel utilisé en cours. Les enseignants semblent conscients des dangers de la stéréotypisation, sans pour autant proposer une alternative viable :

Extrait 5

INT 8.2 : Est-ce que vous pensez que tous les Français pratiquent la même culture ? Je veux dire, les Français sont pareils ou...? 
NNL5 8.2 : Je pense que si on dit ça, je pense que cela mène à des stéréotypes, on a tendance à les stéréotyper, alors je n'aime pas dire qu'ils ont la même culture ou que... parce que je pense que ça mène à des stéréotypes.

INT 8.3 : Vous dites que ça mène à des stéréotypes, alors quand on enseigne la culture française aux étudiants, vous pensez que ça va les amener à stéréotyper les Français?

NNL5 8.3 : Non, peut-être qu'on peut dire que c'est comme ça qu'ils vivent, mais ce n'est pas ce que ça veut dire... On leur apprend comment ils vivent, comment ils réagissent, c'est comment ils... leur manière de vivre, mais on ne dit pas les Français sont comme ci, les Malais sont comme ça. On peut peut-être enseigner ce qu'est leur culture de manière positive, ne pas tous les mettre dans la même boîte, et dire c'est comme ça les Français, c'est comme ça les Malaisiens.

Alors que NNL5 circonscrit la culture au niveau national, INT essaie de relativiser le " nationalisme méthodologique » (Dervin, 2013). NNL5 a de prime abord une approche fluide de la culture. Il/Elle refuse d'inscrire l'ensemble des Français dans une manière de faire/d'être commune. Cependant, ce discours est influencé par des voix extérieures: "je n'aime pas dire qu'ils ont la même culture » fait apparaître un jugement négatif de ce qui pourrait constituer des stéréotypes. NNL5 enseigne dans une université et les stéréotypes ont mauvaise presse dans les milieux académiques; ils sont mal-aimés (Amossy et Herschberg-Pierrot, 1997) et les enseignants essaient de s'en détacher. NNL 5 d'ailleurs voudrait enseigner «leur culture de manière positive » sans se rendre compte qu'il s'agit ici aussi d'enseigner des stéréotypes, sentiment renforcé par le déterminant possessif et l'utilisation du singulier de culture.

Les différentes valeurs de on, tantôt identifiable et inclusif ( on a tendance à les stéréotyper »), tantôt professoral et exclusif ( On peut peut-être enseigner») signifient les difficultés rencontrées par les enseignants entre ce qui se fait (stéréotyper), qui devient ce qui est enseigné, et son rôle de formateur. Le discours de NNL5 est typiquement janusien: "Je ne veux pas généraliser les Français mais j'explique comment ils réagissent » etc. NL1 tombe dans un piège similaire, entre désir de fluidité et pratique essentialisante :

INT8.4 : Ce que vous voulez dire, c'est qu'on ne peut pas identifier quelqu'un par sa culture nationale?

NL1 8.4: Oui [...] Si tu veux dire par 'chaque Français', ok, c'est le petit déjeuner typique, alors tu as tendance à stéréotyper. Alors ce que je veux dire, c'est qu'il y a des similarités, qui feraient que tous les Français font comme... tous les Français pratiquent la même culture, tous les Malaisiens pratiquent la même culture, mais j'ai vraiment peur de stéréotyper, alors je ne veux pas apprendre à mes étudiants, ok, en France... c'est comme ça, comme ça ou comme ça parce qu'ils peuvent aller dans un monde qui est complètement différent [...].

NL1 exprime une situation inconfortable. Il/Elle se rend compte que tout ce qu'il/elle peut dire peut être interprété comme une généralisation, mais on sent en revanche la pression pour formuler ce type d'énoncés. NL1 est conscient que même des notions a priori anodines comme la composition du petit-déjeuner peuvent ne pas refléter la réalité, et il/elle désire vraiment s'éloigner de tout stéréotype. La pression extérieure est forte ("j'ai peur de stéréotyper») pouvant remettre en cause sa position d'enseignant dans une université : Si ce que j'enseigne est faux, alors ma réputation sera entachée. NL1 n'offre cependant aucune alternative, se cantonnant dans le silence par défaut: Je ne veux pas dire, je ne veux pas qu'ils pensent, car il/elle se situe encore à un niveau sociétal imaginé au lieu de prendre en compte la fluidité des cultures et de 
passer au niveau personnel, individuel des interactions. NL1 ne recourt pas au contexte malaisien pourtant riche qui permettrait de parler de diversité à peu de frais.

Les extraits d'entretiens que nous avons présentés ici font apparaître un certain désarroi des enseignants de langue étrangère. Les systèmes éducatifs les poussent à enseigner la culture de pays dont ils enseignent la langue, sans que les attentes soient clairement définies et alors que le concept est hautement problématique. On peut observer une tendance à l'essentialisation des populations étudiées, c'est-à-dire à une réduction des individus à leur "caractéristiques culturelles ». Les manuels utilisés en cours de langue importés d'Europe ont tendance à encourager ce biais, mais qu'en est-il des cours dits de "culture française »? Aucun de nos participants n'a par exemple mentionné des espaces hors de l'Hexagone : les DOM-TOM, la Belgique, le Canada ou même les autres territoires de la Francophonie. L'association « une langue-une culture » domine encore la didactique des langues et cultures étrangères dans le cas du français en Malaisie.

En revanche, les enseignants sont conscients des pièges des stéréotypes dont ils souhaiteraient s'éloigner. Conscients d'une diversité au sein des sociétés étudiées ou dans laquelle ils habitent, ils semblent cependant dépourvus quand ils se retrouvent en situation de classe et retombent assez souvent dans des méthodes comparatives, que ce soit consciemment ou par défaut d'autres méthodologies à leur disposition. Cette opposition culture source-culture cible concerne autant les locuteurs natifs que les enseignants non-natifs (Chin, 2013), indépendamment de leur parcours universitaires, et nous pouvons parler de pratique janusiennes: Je ne veux stéréotyper ou généraliser mais en France/en Malaisie, habituellement on fait comme cela. Les stéréotypes qu'ils essaient de fuir les rattrapent à chaque étape pour finalement s'imposer. Il serait grand temps que davantage de matériels pédagogiques s'engageant sur le chemin de la diversité liquide soient développés et surtout promus afin qu'une réelle fluidité des cultures et des individus puisse être prise en compte. Des pistes existent déjà (voir Dervin, 2012), mais il faudrait leur donner plus de voix encore pour qu'enfin les enseignants de LE puissent se détacher de ces encombrants stéréotypes. L'expérience personnelle des enseignante-s est insuffisante : un changement de paradigme didactique s'impose.

\section{BIBLIOGRAPHIE}

ABDALLAH-PRETCEILLE M., Vers une pédagogie interculturelle, Paris, Anthropos, 1986.

ABDALLAH-PRETCEILLE M., L'éducation interculturelle, Paris, PUF, 1999. AMOSSY R., HERSCHBERGPIERROT, A., Stéréotypes et clichés, Paris, Nathan université, 1997.

ASMAH H. O., « Language Planning and Image Building : The Case of Malay in Malaysia », in International Journal of The Sociology of Language, vol. 130, no 1, 2009, pp. 49-66.

BAUMAN Z., Liquid Modernity, Cambridge, Polity Press, 2001.

BEACCO, J.-C., Les dimensions culturelles des enseignements des langues, Paris, Hachette, 2000. 
BEHRENT S., «Langue véhiculaire et langue cible commune : la communication interalloglotte », in Dervin, F. (dir.), Lingua Francas : La véhicularité linguistique pour vivre, travailler et étudier, L'Harmattan, 2010, pp. 49-67.

BREIDENBACH J., NYÍRI, P., Seeing culture everywhere, Seattle, University of Washington Press, 2009.

CHARAUDEAU P., « Langue, discours et identité culturelle », in Revue de didactologie des languescultures, no 123, 2001, pp. 341-348.

CHIN S.Z., « Foreign Language Lecturers in Malaysia and Interculturality : Common (Mis-) understandings », in International Journal of Education for Diversities (IJE4D), vol. 2, 2013, pp. 62-75.

DERVIN F., Impostures interculturelles, Paris, L'Harmattan, 2012.

DERVIN F., « Researching Identity and Interculturality : from Methodological Nationalism, Transnationalism, to Mixed Intersubjectivity », in Machart, R., Lim, C.B., Lim, S.N., Yamato, E. (dir.), Intersecting Identities and Interculturality: Discourseand Practice, Newcastle-Upon-Tyne, Cambridge Scholars Publishing, 2013, pp. 8-27.

DERVIN F., « Reflections on the Deconditioning of Language Specialists in Finnish Higher Education ", in Dervin, F, Suomela-Salmi, E. (eds.), Intercultural Communication and Education, Finnish Perspectives, Bern, Peter Lang, 2006, pp. 105-125.

DERVIN F., MACHART, R., BYRD CLARK J., « Let's Put an End to the 'Hijacking' of Diversity... », in International Journal of Education for Diversities (IJE4D), vol. 2, 2013, pp. i-v.

HOLLIDAY A., Intercultural Communication and Ideology, London, Sage, 2010.

HOUSSAYE J., Théorie et pratique de l'éducation scolaire : Le triangle pédagogique, Berne, Peter Lang, 1992.

JENKINS J., English as a Lingua Franca : Attitude and Identity, Oxford, Oxford University Press, 2007.

KACHRU Y., NELSON, C.L., World Englishes in Asian Contexts,Hong Kong, Hong Kong University Press, 2006.

LACASSAGNE, M.-F., SALES-WUILLEMIN, É., CASTEL, P., JEBRANE, A., « La catégorisation d'un exogroupe à travers une tâche d'association de mots ", in Papers on Social Representations/ Textes sur les représentations sociales, no10, 2001, pp. 7-11.

LAVANCHY A., GAJARDO, A., DERVIN, F., « Interculturality at stake », in Dervin, F., Gajardo, A., Lavanchy, A. (dir.), Politics of interculturality, Newcastle-upon-Tyne, Cambridge Scholars Publishing, 2011, pp. 1-26.

LIM D.C.L., Overcoming Passion for Race in Malaysia Cultural Studies, Leiden, Brill, 2008.

LIM S.N., MACHART, R., «L'expansion du français en contexte multilingue 'saturé' : Le cas de la Malaisie ", in Synergies Chili, $\mathrm{n}^{\circ}$ 9, 2013. Consultable sur le site : gerflint.eu/publications/synergieschili.html

MACHART, R., LIM, S.N., « De la diversité des écoles à la diversité à l'école : L'école primaire malaisienne en questions ", in Revue internationale d'éducation de Sèvres, no 63, 2013a, pp. 67-75.

MACHART R., LIM, S.N., «Identity and Language vs Identification through Language : A Historical Perspective », in Machart, R., Lim, C.B., Lim, S.N., Yamato E. (dirs.), Intersecting Identities and Interculturality : Discourse and Practice, Newcastle-Upon-Tyne, Cambridge Scholars Publishing, 2013b, pp. 22-44 . 
MACHART R., LIM S.N., CHOONG, Y.L, «L'enseignant non-natif en Malaisie, un enseignant avant d'être non natif ? Étude des représentations d'étudiants malaisiens à travers un test d'association de mots ", in Dervin, F., Badrinathan,

V. (dirs.), L'enseignant non-natif: identités et légitimité dans l'enseignement-apprentissage des langues étrangères, Fernelmont, E.M.E. Editions, 2011, pp. 139-166.

MACHART R., LIM, S.N., LIM C.B., « Chinois de Malaisie et langues européennes, une question d'affinités ", in Dervin, F. (dir.), Lingua Francas : La véhicularité linguistique pour vivre, travailler et étudier, Paris, L'Harmattan, 2010, pp. 213-228.

MCARTHUR T., The Oxford Guide to World Englishes, Oxford, Oxford University Press, 2002.

MAURER B. Représentations sociales des langues en situation multilingue : La méthode combine d'analyse d'enquête, Paris, Editions des archives contemporaines, 2013

PHILIPPSON R., « Lingua franca or lingua frankensteinia ? English in European integration and globalization », in World Englishes, vol. 27, No 2, 2008, pp. 250-267.

POUTIGNAT P., STREIFF-FENART, J., Théories de l'ethnicité. Suivi de : Les groupes ethniques et leurs frontières, Paris, PUF, 2008.

RIGET P., « Pertinence de la formation en France et adéquation aux besoins malaisiens : entre théorie et pratiques ", in Machart, R., Dervin, F. (dir.), Les nouveaux enjeux des mobilités et migrations académiques, Paris, L'Harmattan, 2014, pp. 93-151.

THIESSE A.-M., La Création des identités nationales : Europe XVIIIe-XIXe siècle, Paris, Le Seuil, 1999.

VOLLE R.-M., « La mobilité académique aujourd'hui : Vers un repli du savoir sur la compétence? ", in Machart, R., Dervin, F. (dir.), Les Nouveaux enjeux des mobilités et migrations académiques, Paris, L'Harmattan, 2014, pp. 73-92. WELSCH W., « Transculturality - The Puzzling Form of Cultures Today », in Featherstone, M., Lash, S., (dir.), Spaces of Culture : City, Nation, World, London, Sage, 1999, pp. 194-213.

WIMMER A., Ethnic Boundaries Making, Oxford, Oxford University Press, 2013.

ZARATE, G., Représentations de l'étranger et didactique des langues, Paris, Crédif Essais, 2004.

\section{RÉSUMÉS}

La Didactique de la culture et de l'interculturel s'inscrivent souvent dans une approche solide, faisant fi de la diversité fondamentale de chaque culture. Les enseignants se retrouvent confrontés à un dilemme : comment enseigner la culture de l'Autre sans tomber dans le piège des stéréotypes? Cette contribution analyse le discours d'enseignants de français en Malaisie, pays multiculturel et multilingue et questionne leurs ancrages théoriques de la culture. Il fait apparaitre un besoin urgent de davantage de matériel pédagogique prenant en compte une plus grande diversité pour la classe.

The Didactics of culture and interculturality often follows a solid approach, ignoring the fundamental diversity of each culture. Lecturers are confronted with a dilemma: How to teach the 'culture' of the Other without falling into the trap of stereotyping? This contribution analyzes the discourse of French lecturers in Malaysia, a multicultural and multilingual country, and questions their theoretical framework of culture. It appears that more teaching material which takes into account agreater sense of diversity is needed for the classroom. 


\section{INDEX}

Keywords : fluid interculturality, didactics of culture, Malaysia, stereotypes

Mots-clés : interculturalité fluide, didactique de la culture, Malaisie, stéréotypes

\section{AUTEURS}

\section{REGIS MACHART}

Universiti Putra

Malaisie

Regis MACHART est maître de conférences à la Faculty of Modern Languages and Communication, Universiti Putra de Malaisie. Il est spécialisé en analyse du discours, sociolinguistique, cultural Studies.

Il est co-auteur de deux ouvrages :

Machart R., Lim C.B., Lim S.N. \& Yamato E. Eds, Intersecting Identities and Interculturality : Discourse and Practice, Cambridge Scholars Publishing, 2013.

Machart, R. \& F. Dervin (Eds), Les nouveaux enjeux des mobilités et migrations académiques, Paris, L'Harmattan, 2014.

Il est l'auteur de chapitres dans plus d'une dizaine d'ouvrages dont :

Machart, R., L'Amant de Marguerite Duras (1984) : simple "miscegenation" ou relation coculturelle? Dans Dervin, F. (ed.), Relations intimes interculturelles (pp. Paris : Archives contemporaines, 2013.

Machart, R., Bienvenue chez les Ch'tis ou les actifs de l'essentialisme stratégique. Dans Dervin, F. Le concept de culture ; comprendre et maîtriser ses détournements et manipulations (pp. 121-144). Paris : L'Harmattan, 2013.

Machart, R. \& Lim S.N., « Mobilité académique et ajustement au contexte d'accueil : La fin du choc culturel ? ", dans Machart, R. And F. Dervin, Les nouveaux enjeux des mobilités et migrations académiques, L'Harmattan, 2014.

Il a publié de nombreux articles parmi lesquels :

Machart, R., Lim, S.N. \& Ungureanu, C., « Les Européens tels que les Roumains se les représentent quatre ans après l'adhésion à l'UE : Une intégration réussie ? ", Synergies Roumanie, nº 6, 2011, pp. 223-234.

Dervin, F., Machart, R. \& Byrd Clark, J., Towards education for diversities? International Journal of Education for Diversities, 2012, 1 : i-iv.

Machart, R. \& Lim, S.N., « De la diversité des écoles à la diversité à l'école ? L'école primaire malaisienne en questions ", in Revue internationale d'éducation de Sèvres, 2013, pp. 7-75.

Lim, S.N. \& R. Machart, « L'expansion du français en contexte multilingue 'saturé' : Le cas de la Malaisie », Synergies Chili, n 9, 2013, pp 51-61.

\section{SIN ZI CHIN}

\section{Universiti Putra - Malaisie}

CHIN Sin Zi est étudiante, à la Faculty of Modern Languages and Communication, Universiti Putra de Malaisie, en Master de français langue étrangère-analyse du discours. Elle est l'auteur de l'article « Foreign Language Lecturers in Malaysia and Interculturality : Common (Mis-) understandings ", in International Journal of Education for Diversities (IJE4D), vol. 2, 2013, pp. 62-75. 